\title{
A mechanism-based computational model to capture the interconnections among epithelial-mesenchymal transition, cancer stem cells and Notch-Jagged signaling
}

\author{
Federico Bocci, ${ }^{1,2}$, Mohit Kumar Jolly ${ }^{1}$, Jason Thomas George ${ }^{1,3,6}$, Herbert Levine ${ }^{1,2,3,4}$ \\ and José Nelson Onuchic ${ }^{1,2,4,5}$ \\ ${ }^{1}$ Center for Theoretical Biological Physics, Rice University, Houston, TX 77005, USA \\ ${ }^{2}$ Department of Chemistry, Rice University, Houston, TX 77005, USA \\ ${ }^{3}$ Department of Bioengineering, Rice University, Houston, TX 77005, USA \\ ${ }^{4}$ Department of Physics and Astronomy, Rice University, Houston, TX 77005, USA \\ ${ }^{5}$ Department of Biosciences, Rice University, Houston, TX 77005, USA \\ ${ }^{6}$ Medical Scientist Training Program, Baylor College of Medicine, Houston, TX 77030, USA \\ Correspondence to: José Nelson Onuchic, email: jonuchic@rice.edu \\ Herbert Levine, email: herbert.levine@rice.edu \\ Keywords: epithelial-mesenchymal transition (EMT); cancer stem cells (CSCs); Notch signaling; hybrid epithelial/mesenchymal \\ (E/M) phenotype; stemness window \\ Received: May 05, $2018 \quad$ Accepted: June 13, $2018 \quad$ Published: July 06, 2018 \\ Copyright: Bocci et al. This is an open-access article distributed under the terms of the Creative Commons Attribution License 3.0 \\ (CC BY 3.0), which permits unrestricted use, distribution, and reproduction in any medium, provided the original author and source \\ are credited.
}

\section{ABSTRACT}

Epithelial-mesenchymal transition (EMT) and cancer stem cell (CSCs) formation are two fundamental and well-studied processes contributing to cancer metastasis and tumor relapse. Cells can undergo a partial EMT to attain a hybrid epithelial/mesenchymal (E/M) phenotype or a complete EMT to attain a mesenchymal one. Similarly, cells can reversibly gain or lose 'stemness'. This plasticity in cell states is modulated by signaling pathways such as Notch. However, the interconnections among the cell states enabled by EMT, CSCs and Notch signaling remain elusive. Here, we devise a computational model to investigate the coupling among the core decision-making circuits for EMT, CSCs and Notch. Our model predicts that hybrid E/M cells are most likely to associate with stem-like traits and enhanced Notch-Jagged signaling - a pathway implicated in therapeutic resistance. Further, we show that the position of the 'stemness window' on the 'EMT axis' is varied by altering the coupling strength between EMT and CSC circuits, and/or modulating Notch signaling. Finally, we analyze the gene expression profile of CSCs from several cancer types and observe a heterogeneous distribution along the 'EMT axis', suggesting that different subsets of CSCs may exist with varying phenotypes along the epithelial-mesenchymal axis. We further investigate therapeutic perturbations such as treatment with metformin, a drug associated with decreased cancer incidence and increased lifespan of patients. Our mechanism-based model explains how metformin can both inhibit EMT and blunt the aggressive potential of CSCs simultaneously, by driving the cells out of a hybrid E/M stem-like state with enhanced Notch-Jagged signaling.

\section{INTRODUCTION}

Metastatic spread of cancer cells claims the highest number of fatalities, accounting for over $90 \%$ of cancer-related deaths [1]. Studies in mouse models have suggested that a large percentage of metastases are formed by clusters of Circulating Tumor Cells (CTCs) cohesive units of two or more CTCs that are launched into the bloodstream as aggregates [2]. Consistently, clinical data highlights that the presence of clusters of CTCs 
correlate with higher aggressiveness and shorter patient survival across cancer types [3]. Thus, understanding the mechanisms that contribute to the formation and enhanced metastatic ability of these clusters holds promise for unraveling novel therapeutic strategies.

To enter the bloodstream as clusters of CTCs, epithelial cancer cells in primary solid tumors typically partially lose their cell-cell adhesion with their neighbors, and simultaneously acquire mesenchymal traits of motility and invasion. Such a hybrid epithelial/mesenchymal (E/M) phenotype, also referred to as a partial epithelialmesenchymal transition (pEMT) state, facilitates clustered or collective cell migration [4, 5]. A core regulatory circuit that receives multiple inputs and controls many molecular and morphological aspects of EMT consists of two families of microRNAs (miR-34 and miR-200) and two families of EMT-inducing transcription factors (EMTTFs) (SNAIL and ZEB) [6] (Figure 1, EMT module). High levels of miR-34 and miR-200, and low levels of SNAIL and ZEB correspond to an epithelial (E) state; an opposite configuration with (low miR-34 and miR-200, high SNAIL and ZEB) corresponds to a mesenchymal (M) state [7-9]. An intermediate expression of these microRNAs and EMT-
TFs has been proposed to correspond to a hybrid E/M state, exhibiting both cell-cell adhesion and cell motility [4].

Once individual CTCs and/or CTC clusters exit the bloodstream at a distant organ, they need to form secondary tumors. All three phenotypes - epithelial, mesenchymal, and hybrid E/M - have been correlated with possessing stemness, i.e. tumor-initiation ability [10-12], in different systems. Thus, the 'stemness window' can move along the EMT axis [13], and a precise mechanistic connection between EMT and cancer stem cells (CSCs) remains elusive. In many cases, a mutually inhibitory feedback loop between LIN-28 and let-7 regulates the tendency of a cell to behave as a CSC [14]. This loop can behave as a three-way switch [15] by giving rise to three possible states: (i) a (low LIN-28, high let-7), or DOWN (D) state; (ii) a (high LIN28, low let-7), or UP (U) state; and (iii) a (intermediate LIN28 , intermediate let-7), or DOWN/UP (D/U) state (Figure 1, STEM module). Since intermediate levels of OCT4, a direct target of LIN-28, has been observed to correlate with stemlike properties $[16,17]$, the $\mathrm{D} / \mathrm{U}$ state was proposed to be associated with stemness.

Additionally, cell-cell signaling through the Notch signaling pathway has been implicated in modulating

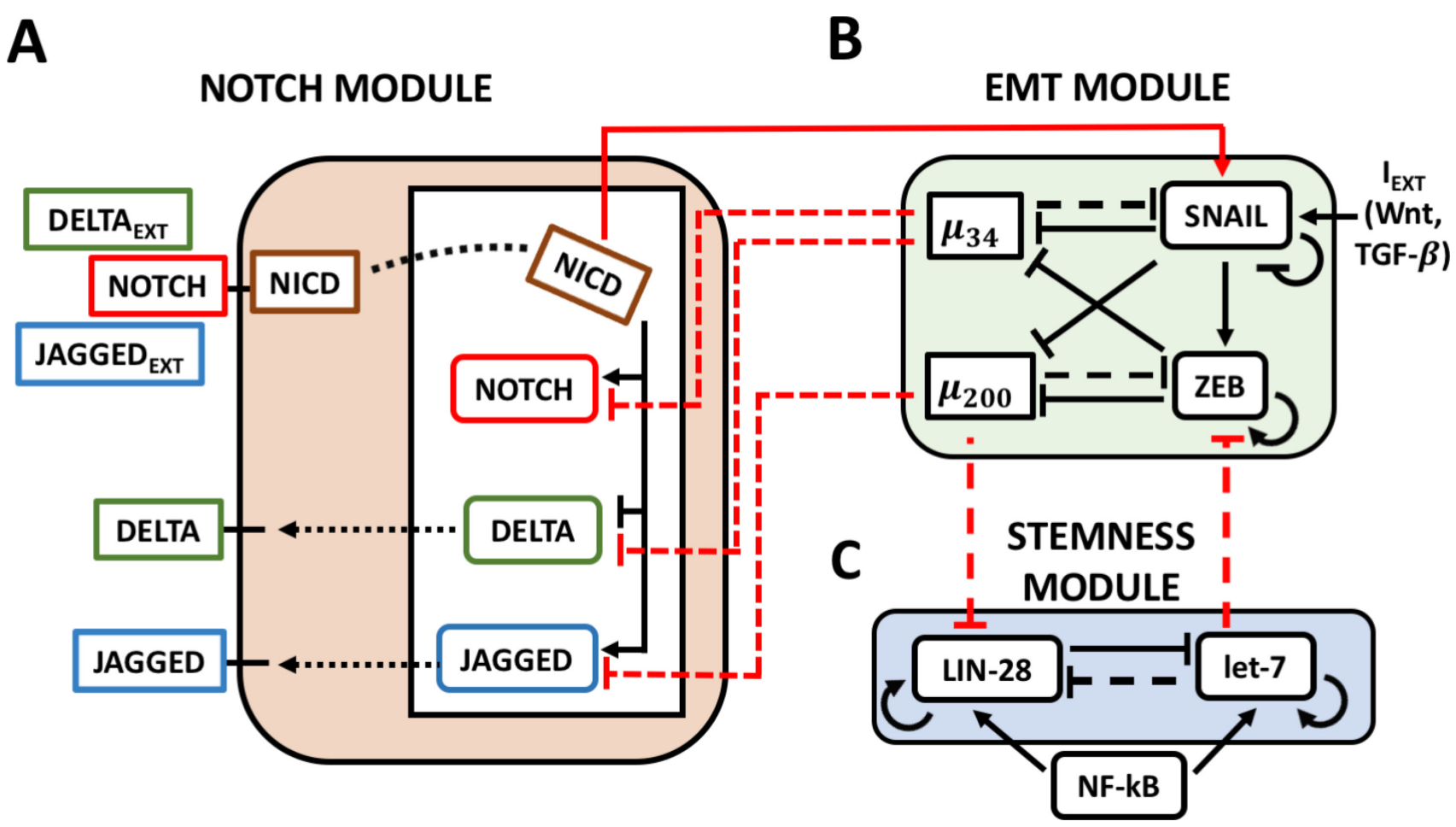

Figure 1: The Notch-EMT-STEM decision-making circuit. (A) The Notch circuit receives external ligands (Delta/Jagged) as inputs that bind to Notch on the surface. This results in the cleavage of Notch which generates NICD. NICD translocates to the nucleus where it transcriptionally activates Notch and Jagged while inhibiting Delta. (B) The EMT module contains two micro-RNA families (miR-34, miR-200) and two transcription factor families (SNAIL, ZEB) which mutually repress each other. External signals such as Wnt or TGF-beta activate SNAIL and promote EMT. (C) In the STEM module, LIN-28 and let-7 mutually repress each other, while both can selfactivate. Additionally, external NF- $\mathrm{KB}$ signaling activates both. Solid lines stand for transcriptional/translational interactions (let-7 autoregulates its maturation), while dotted lines represent post-translational inhibition. The connections between the modules are highlighted in red: NICD transcriptionally activates SNAIL; miR-34 post-translationally inhibits Notch and Delta, while miR-200 inhibits Jagged; miR-200 and let-7 post-translationally inhibit LIN-28 and ZEB respectively. 
EMT, enhancing therapeutic resistance [18], expanding the CSC population $[19,20]$, and in the formation of clusters of CTCs [21, 22]. Notch signaling is an evolutionarily conserved cell-cell signaling pathway [23] which includes a family of trans-membrane receptors (Notch) and two families of ligands (Delta, Jagged). The binding of one cell's receptor to a neighbor cell's ligand results in the cleavage of the Notch Intra-Cellular Domain (NICD), which translocates to the nucleus and regulates several target genes, including activating Notch and Jagged, but repressing Delta (Figure 1, Notch module). In the presence of a strong Notch-Delta signaling, a cell can either attain a (high Notch, low Delta) Receiver (R) state or a (low Notch, High Delta) Sender (S) state. Conversely, predominance of signaling toward the Notch-Jagged pathway culminates in a (high Notch, high Jagged) Sender/Receiver (S/R) state $[24,25]$.

Here, we develop a mechanism-based mathematical model to elucidate the interconnections between EMT, CSCs and Notch signaling, by investigating the emergent dynamics due to the coupling among the EMT, STEM and NOTCH modules. We find that stemness traits tend to co-exist with a hybrid epithelial-mesenchymal (E/M) phenotype and strong Notch-Jagged signaling. Modulation by external signaling pathways can decouple the abovementioned correlation, suggesting that stem-like traits need not be exclusively correlated with a specific EMT phenotype. To validate this prediction, we examine the gene expression profile of CSCs from several cancer subtypes and find a heterogeneous distribution for the 'stemness window' along the 'EMT axis', thus enabling the existence of subsets of CSCs with epithelial, hybrid $\mathrm{E} / \mathrm{M}$ or mesenchymal phenotypes. Lastly, we apply our formalism to model the action of metformin in targeting CSCs and inhibiting EMT, providing a mechanism-based explanation for several experimental findings, including decreased Notch1 levels in metformin-treated pancreatic cancer cells [26], metformin inhibition of TGF-beta induced EMT [27] and the recovery of stem-like traits upon NF-кB overexpression in metformin-treated cells [28].

\section{RESULTS}

\section{A mathematical framework to couple Notch signaling, epithelial-mesenchymal transition and stemness}

To elucidate the outcome of interconnections among Notch signaling, EMT and stemness, we hereby develop a mechanism-based mathematical framework that integrates the experimentally identified connections among these three crucial pro-metastatic modules, and explore any correspondence between the cell states enabled independently by these three modules.

Given that each of the modules-Notch, EMT and STEM-can give rise to three different cell states independently, their coupling can possibly give rise to as much as $27=3^{3}$ states combining the (S, S/R, R), (E, E/M, $\mathrm{M})$ and $(\mathrm{D}, \mathrm{D} / \mathrm{U}, \mathrm{U})$ states. Coupling between the modules can, however, introduce correlations which lower this to a much smaller number. The three modules are connected as follows (see red arrows on Figure 1): (a) Active Notch signaling (NICD) promotes EMT through activating EMT-TF SNAIL and therefore increasing its cellular production rate constant by a fold-change factor $\lambda_{\text {SNAIL }}>1$ [29, 30]; (b) miR-34 and miR-200 act as post-translational inhibitors of Notch receptor and ligands, therefore increasing their degradation rate, hence shunting the activation of the Notch pathway [31-33]; and (c) LIN-28 and ZEB are post-translational targets of micro-RNAs miR-34 and let-7, respectively [13], thus, miR-34 and let-7 decrease the production rate constants of LIN-28 and ZEB by factors $\lambda_{\text {LIM-28 }}, \lambda_{\text {ZEB }}<1$, respectively (see Methods).

To investigate the cell-fate dynamics of this coupled network, we set up a mathematical model for the EMTSTEM-Notch coupled circuit (see Methods). The output of our model is a cell phenotype defined as a combination of (EMT, STEM, Notch) phenotype, depending on baseline conditions and strengths of interactions among these three modules.

\section{Emergence of a coupling among hybrid E/M, stem-like, and sender/receiver ( $\mathrm{S} / \mathrm{R})$ states}

As the first step to investigate the coupling among states of Notch signaling, EMT, and stemness (i.e. STEM module), we examined how an epithelial cell responds to varying levels of external Notch ligands $L_{E X T}$ (either Delta or Jagged).

Following the binding of Delta or Jagged to Notch, Notch signaling is activated and stimulates EMT, thereby decreasing the levels of miR-34 and miR-200, while increasing those of SNAIL and ZEB (Figure 2A and Supplementary Figure 1). This progression to EMT is achieved in two steps - transition from an epithelial state to a hybrid E/M state, and transition from a hybrid E/M state to a mesenchymal state. Specifically, an intermediate exposure to Notch ligands may enable cells to stably maintain a hybrid E/M state (yellow shaded horizontal region in Figure 2A). LIN-28 is inhibited by miR-200 (Figure 1) and is therefore upregulated by the external Notch stimulus (Figure 2B). Interestingly, projecting the stability region of the hybrid E/M state onto the LIN28 bifurcation diagram revealed a significant overlap between a hybrid E/M state (yellow shaded vertical region in Figure 2B) and intermediate LIN-28 levels (violet shaded horizontal region in Figure 2B) corresponding to a DOWN/UP (D/U), or stem-like, state. Further, this stemlike hybrid E/M phenotype overlaps significantly with high Notch Intracellular Domain (NICD), which in turn biases the cell toward a (high Notch, high Jagged), i.e. hybrid S/R phenotype (Figure 2C). 
Taken together, these results highlight a strong correlation between a hybrid S/R Notch state, a hybrid $\mathrm{E} / \mathrm{M}$ phenotype, and the expression of stem-like traits, or a $\mathrm{D} / \mathrm{U}$ state. In other words, cells in a hybrid $\mathrm{E} / \mathrm{M}$ phenotype are highly likely to exhibit stem-like properties and show enhanced Notch-Jagged signaling. Indeed, cells co-expressing various epithelial and mesenchymal genes display enhanced JAG1 levels in circulating tumor cell (CTC) clusters and in drug-tolerant breast cancer cells [21]. Thus, this proposed overlap of hybrid E/M, stemlike traits, and Notch-Jagged signaling is supported by preliminary experimental evidence.

In the following sections, we will refer to the modes of the EMT module (E, E/M, M) as states because they have a one to one correspondence with the mathematical solutions of the model. In other words, each branch of the bifurcation diagram of Figure 2A can be associated with a distinct EMT phenotype. Conversely, the modes of the Notch module ( $, S / R, R)$ and STEM module (D, D/U, $\mathrm{U})$ will be referred to as 'phenotypes' because they are defined based on threshold levels of (Notch, Jagged) and LIN-28, respectively rather than on the branches of the diagrams of Figure 2B-2C (see Methods for details).

\section{Varying the coupling strengths of EMT and STEM modules can enable shifts in the positioning of the "stemness window" on the EMT axis}

To investigate the robustness of overlap among hybrid E/M, stem-like traits, and enhanced Notch-Jagged signaling, we varied the strength of two links in our network: the cellular production fold-change of LIN-28 due to inhibition by miR-200 $\left(\lambda_{L I M-28}\right)$, and the cellular production fold- change of ZEB due to inhibition by let-7 $\left(\lambda_{Z E B}\right)$ [13]. These parameters can be varied from 0 (very strong repression) to 1 (no repression), generating a full spectrum, or diagram, of EMT-STEM coupling interactions. It should be noted that in our circuit, NOTCH and STEM modules are not directly coupled (Figure 1).

First, we consider a cell exposed to an intermediate level of external Notch ligands. Such a cell will have intermediate NICD levels, and thus can attain a hybrid $\mathrm{E} / \mathrm{M}$ state in the absence of connection between the EMT and STEM modules (Figure 3A). The EMT and STEM diagrams highlight large parameter regions where the hybrid E/M and the $\mathrm{D} / \mathrm{U}$ stem-like states are available to the cell, either as the only solution or as one of the two bistable solutions $(\{\mathrm{E} / \mathrm{M}\},\{\mathrm{E}, \mathrm{E} / \mathrm{M}\}$ phases in Figure $3 \mathrm{~B}$, and $\{\mathrm{D} / \mathrm{U}\},\{\mathrm{D}, \mathrm{D} / \mathrm{U}\},\{\mathrm{D} / \mathrm{U}, \mathrm{U}\}$ phases in Figure $3 \mathrm{C})$. In particular, a strong repression of ZEB by let-7 pushes the cell toward an epithelial state $\left(\lambda_{Z E B}\right.$ close to 0 in Figure $3 \mathrm{~B}$ and Figure 3D), consistent with experimental observations that depleting ZEB1 can push pancreatic cancer cells towards an epithelial phenotype [34]. Similarly, increasing the strength of repression of LIN28 by miR-200 (i.e. reducing $\lambda_{L I N-28}$ from 1 to 0 ) induces a shift from a $U$ to a $\mathrm{D} / \mathrm{U}$ to a $\mathrm{D}$ state (Figure $3 \mathrm{C}$ and Figure $3 \mathrm{D}$ ). Overlapping the EMT and STEM maps highlights a large $\{\mathrm{E} / \mathrm{M}-\mathrm{D} / \mathrm{U}\}$ region (darker area in Figure 3D), i.e. a hybrid E/M state overlaps with a stem-like behavior. Additionally, a strong repression of ZEB by let-7 enables maintaining stemlike traits in an epithelial state $\{\mathrm{E}-\mathrm{D} / \mathrm{U}\}$, while hybrid $\mathrm{E} / \mathrm{M}$ states that are not stem-like can be observed for very strong $\{\mathrm{E} / \mathrm{M}-\mathrm{D}\}$ or very weak $\{\mathrm{E} / \mathrm{M}-\mathrm{U}\}$ inhibition of LIN-28 by miR-200 (Figure 3D).

We repeated the abovementioned analysis, when the cell is exposed to a high level of external Notch ligands,
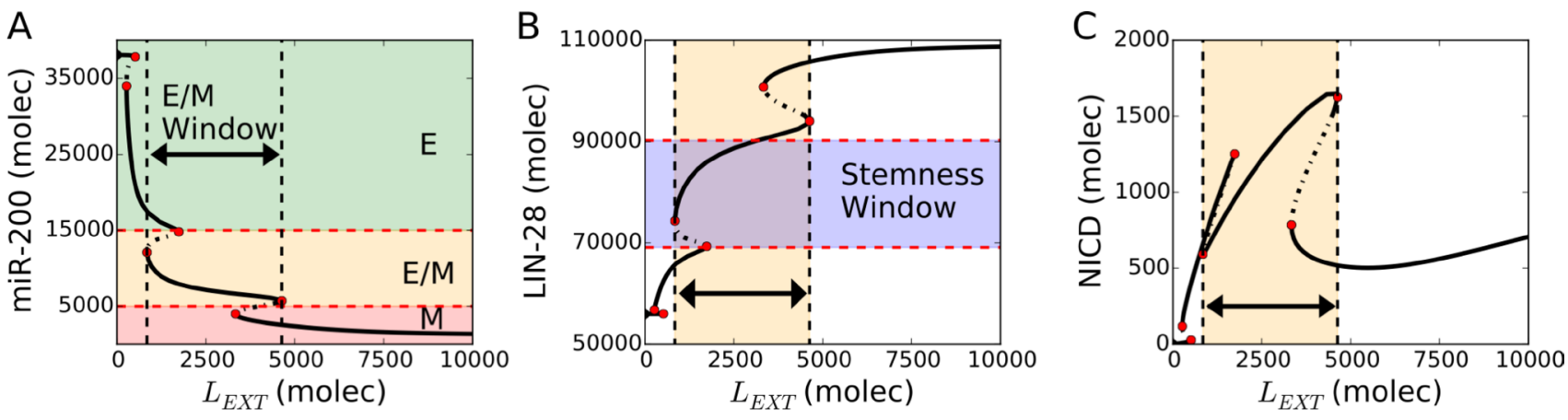

Figure 2: Notch-induced EMT couples hybrid E/M, stem and sender/receiver (S/R) states. (A) Bifurcation diagram of the cellular level of microRNA 200 (miR-200) as a function of external Notch ligands $L_{E X T}$ (Delta + Jagged). Continuous and dotted black lines denote stable and unstable solutions of the model respectively. The thick black horizontal arrow highlights the range of $L_{E X T}$ allowing a hybrid E/M state. Red dotted lines indicate the miR-200 range of epithelial, hybrid E/M and mesenchymal phenotypes. (B) Bifurcation diagram of the cellular levels of LIN-28 in response to $L_{E X T}$. The cell falls into the stemness window at intermediate LIN-28 levels (violet-shaded horizontal region - see Methods for more details about defining the boundaries of stemness window). The yellow vertical region and black arrow highlight the range of $L_{E X T}$ levels enabling a stable hybrid E/M state. (C) Bifurcation diagram of NICD in response to $L_{E X T}$ The hybrid E/M phenotype interval maps onto high levels of NICD corresponding to (high Notch, high Jagged) and therefore to a Sender/Receiver (S/R) phenotype (see Methods for more details about defining the boundaries of the Notch states). For this diagram, the coupling between EMT and STEM circuits is intermediate $\left(\lambda_{L I M-28}=\lambda_{Z E B}=0.5\right)$, external Notch receptor is $N_{E X T}=10^{4}$ molecules and $N F-k B=2.5 * 10^{3}$ molecules. 
and therefore in a mesenchymal state initially (due to Notch-induced EMT) (Figure 3E). In this case, all three EMT states (E, E/M, M) and STEM phenotypes (DOWN, $\mathrm{D} / \mathrm{U}, \mathrm{UP})$ are observed upon variation of the coupling parameters $\left(\lambda_{L I M-28}, \lambda_{Z E B}\right)$ (Figure $\left.3 \mathrm{~F}-3 \mathrm{G}\right)$. Similar to the first case, the regions of the hybrid $\mathrm{E} / \mathrm{M}$ state and the $\mathrm{D} / \mathrm{U}$ phenotype largely overlap (darker region in Figure $3 \mathrm{H}$ ), hence confirming the correlation reported in the Notchdriven EMT. further, a very strong repression of ZEB by let-7 facilitates the existence of epithelial stem-like cells (i.e. $\{\mathrm{E}-\mathrm{D} / \mathrm{U}\}$ ), while very weak repression of $\mathrm{ZEB}$ by let-7 enables the overlap of mesenchymal state with stemlike behavior (i.e. $\{\mathrm{M}-\mathrm{D} / \mathrm{U}\})\left(\lambda_{Z E B}\right.$ close to 0 and close to 1 in Figure $3 \mathrm{~F}$ respectively).

Overall, these results consistently show a strong correlation between hybrid $\mathrm{E} / \mathrm{M}$ and $\mathrm{D} / \mathrm{U}$ stem-like traits across large variation of the coupling strength between the EMT and STEM circuits. Further, other factors such as the activation status of Notch signaling can shift the 'stemness window' across the EMT axis, resulting in epithelial (E-D/U) or mesenchymal (M-D/U) stem cells. Thus, while the 'stemness window' may be likely to lie mid-way on the EMT axis, context-specific differences may shift it towards either end (i.e. E or M) of the EMT axis.

\section{Tuning NF-кB, EMT induction, and Notch activation levels reveal different subpopulations of cancer stem cells (CSCs)}

Crosstalk with intra and/or extra-cellular signaling pathways can modulate the NOTCH, EMT and STEM modules, thus altering their expected outcomes. To incorporate this aspect, we considered three signals that can serve as inputs for the NOTCH-EMT-STEM circuit: (i) external Notch ligands (Delta and Jagged) $L_{E X T}$ activating intra-cellular Notch signaling; (ii) a direct EMT-inducer $I_{E X T}$ that may stabilize or overexpress SNAIL, such as Wnt or TGF- $\beta$; and (iii) NF- $\kappa \mathrm{B}$ signaling activating LIN-28 and let-7 [13].

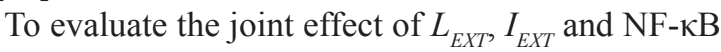
on the region enabling the (high notch, high jagged)-hybrid E/M-stem-like phenotype - or the coupled ' $\mathrm{E} / \mathrm{M}$ - D/U - S/R' state, we set up three phenotype characterization diagrams where two parameters are varied while the third is held constant, and inspect the parameter variation range over which the coupled ' $\mathrm{S} / \mathrm{R}-\mathrm{E} / \mathrm{M}-\mathrm{D} / \mathrm{U}$ ' phenotype exists. For this set of simulations, the connection between EMT and STEM modules is intermediate $\left(\lambda_{\text {LIM-28 }}, \lambda_{Z E B}=0.5\right.$ the central point in the diagrams of Figure 3).
A

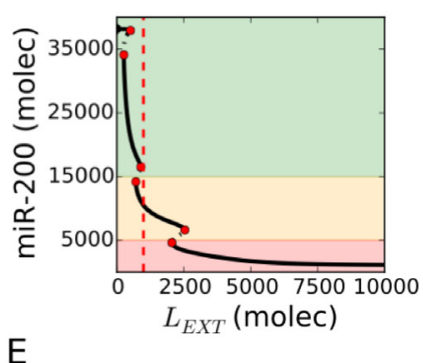

E

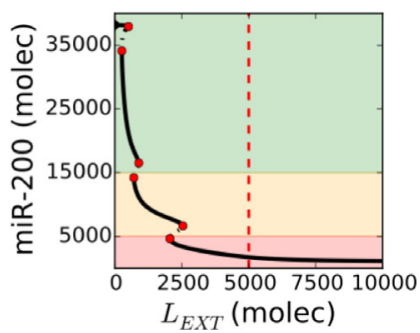

B

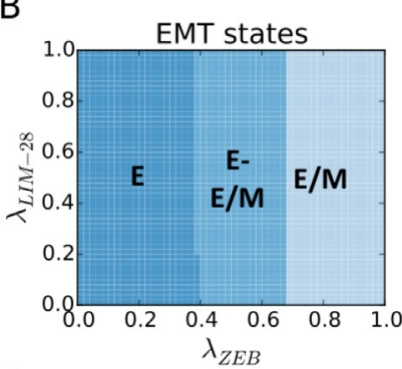

$\mathrm{F}$

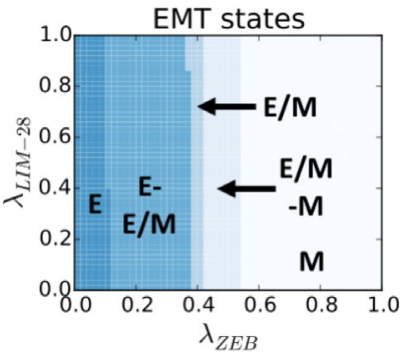

C

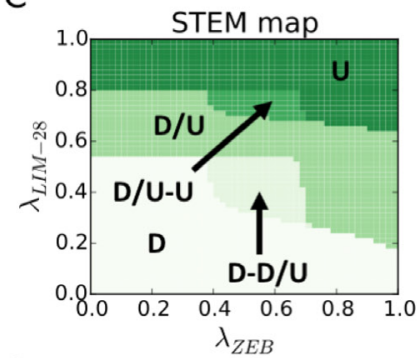

G

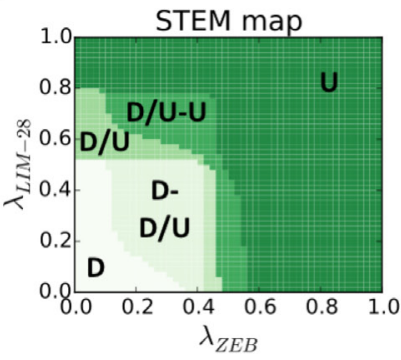

D

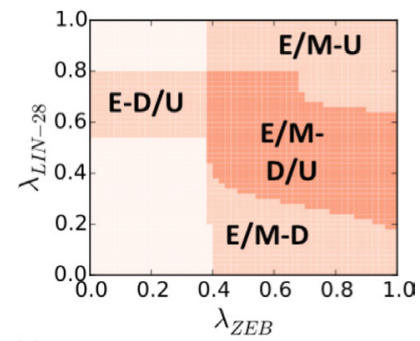

$\mathrm{H}$

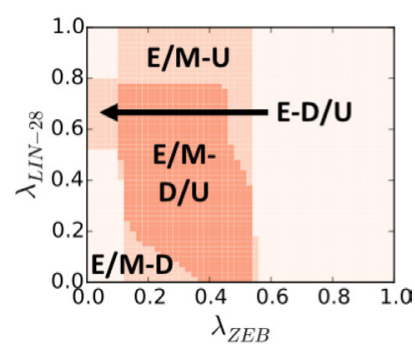

Figure 3: Hybrid E/M and D/U (stem-like) phenotypes overlap over a large variation of EMT-STEM circuit coupling strength. (A) For $L_{E X T}=10^{3}$ molecules and no EMT-STEM coupling $\lambda_{L I M-28}=\lambda_{Z E M}=1$ (first considered condition), the cell expresses a hybrid $\mathrm{E} / \mathrm{M}$ state (see the intersection of the red dotted line with the diagram's continuous lines). (B) EMT state diagram over variation of foldchanges for let-7 inhibition on ZEB ( $\lambda_{Z E M}, \mathrm{x}$-axis) and micro-RNA-200 inhibition on LIN-28 $\left(\lambda_{Z E M-28}, \mathrm{y}\right.$-axis) and for $L_{E X T}=10^{3}$ (panel A). The cell phenotype is described by the state of the EMT module. (C) STEM phenotypic characterization diagram for the conditions of panel A. The cell phenotype is described by the state of the STEM module (Down: D, Stem: STEM, Up: U). (D) Superimposition of the stability regions of hybrid E/M state (panel B) and D/U state (panel C) for the conditions of panel A. Labels highlight the regions where the hybrid $\mathrm{E} / \mathrm{M}$ and/or stem-like D/U are observed. This diagram does not label every combination of EMT and STEM phenotypes but only highlight regions where either hybrid E/M or stem-like D/U (or both) are expressed. (E) For $L_{E X T}=510^{3}$ molecules and no EMT-STEM coupling $\lambda_{Z E M-28}=\lambda_{Z E M}=1$ (second considered condition), the cell expresses a monostable mesenchymal phenotype. (F) EMT state diagram for $L_{E X T}=510^{3}$ (panel E). (G) STEM phenotypic characterization diagram for the conditions of panel E. (H) Superimposition of the stability regions of hybrid $\mathrm{E} / \mathrm{M}$ state (panel $\mathrm{F}$ ) and $\mathrm{D} / \mathrm{U}$ state (panel $\mathrm{G}$ ) for the conditions of panel $\mathrm{E}$. 
First, simulating the coupled modules at a fixed value of $N F-\kappa B$, we found that the ' $S / R-E / M-D / U$ ' phenotype exists for intermediate levels of exposure to Notch ligands $\left(L_{E X T}\right)$ while exposing to EMT induction signal $\left(I_{E X T}\right)$ narrows the stability range of the ' $\mathrm{S} / \mathrm{R}-\mathrm{E} / \mathrm{M}-\mathrm{D} / \mathrm{U}$ ' phenotype (Supplementary Figure 2). Further, fixing the value of EMT inducer shows that a strong down-regulation or overexpression of $\mathrm{NF}-\kappa \mathrm{B}$ restricts the stability of the ' $\mathrm{S} / \mathrm{R}$ - E/M - D/U' phenotype as well (Supplementary Figure $3)$, i.e. the stability of the ' $E / M-D / U-S / R$ ' phenotype is maximized at intermediate values of $\mathrm{NF}-\kappa \mathrm{B}$.

Next, simulating the coupled modules at fixed values of $L_{E X T}$, we observed that a strong EMT-induction $\left(I_{E X T}\right)$ pushes the cell out of the (high Notch, high Jagged) S/R region and into a mesenchymal (M) state, while $\mathrm{NF}-\kappa \mathrm{B}$ overexpression could rescue the existence of $\mathrm{S} / \mathrm{R}$ and $\mathrm{E} / \mathrm{M}$ phenotypes (Figure 4A, 4B). Further, LIN-28 is upregulated in presence of high NF- $\kappa \mathrm{B}$, leading to an UP phenotype (Figure 4C). Overall, high levels of EMT-induction and $\mathrm{NF}-\kappa \mathrm{B}$ push the cell out of the coupled ' $\mathrm{E} / \mathrm{M}-\mathrm{D} / \mathrm{U}-$ $\mathrm{S} / \mathrm{R}$ ' phenotype (Figure 4D). Specifically, a strong EMT induction can result in mesenchymal stem cells $(\mathrm{M}-\mathrm{D} / \mathrm{U}$

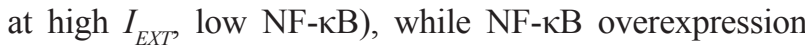
can generate hybrid $\mathrm{E} / \mathrm{M}$ that are not stem-like (E/M-U

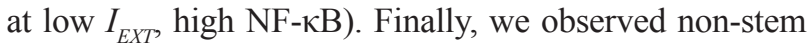
mesenchymal cells when both signaling channels $-I_{E X T}$ ad $\mathrm{NF}-\kappa \mathrm{B}-$ are active (M-U at high $I_{E X T}$, high NF- $\kappa \mathrm{B}$ ).

All possible combinations of stem and non-stem cells undergoing partial or complete EMT were observed, thereby showing that the coupling among EMT, Notch, and STEM modules can give rise to different subpopulations of cancer stem cells (CSCs) with a spectrum of epithelialmesenchymal phenotypes.

There is every reason to suspect that the precise set of phenotypes seen in a given situation depends on the cancer type, it is probably very specific from patient to patient, and perhaps even depend on the specific position within a given tumor $[35,36]$.

\section{Analysis of gene expression profiles reveals epithelial, hybrid $\mathrm{E} / \mathrm{M}$ and mesenchymal cancer stem cells}

To validate our prediction that context-specific interactions can move the 'stemness window' toward the epithelial or mesenchymal end of the 'EMT axis', we analyze the gene expression data of CSCs from different cancer subtypes that have been characterized with stemness markers (such as ALDH+ or CD44+/CD24-) or via other functional assays (Supplementary Table 6). We previously devised an inferential model which predicts the positioning of a given gene expression profile along the 'EMT axis', or 'EMT score', using the expression level of several key EMT regulators as predictors [37]. Among others, the EMT metric score considers canonical epithelial and mesenchymal markers such as E-cadherin and Vimentin as well as 'phenotypic stability factors' (PSFs) which help in stabilizing a hybrid E/M phenotype such as GRHL2 and OVOL. These scores are on a scale of 0 (fully epithelial) to 2 (fully mesenchymal). For each dataset considered here, we computed the 'EMT score' all the cell lines/subpopulations that were reported to express stem-like traits.

CSCs isolated from various non-small cell lung cancer cells - A549 and NCI-H2170 - were identified as either hybrid E/M or mesenchymal. Compared to NCI-H2170, A549 CSCs were enriched in mesenchymal markers CD44 and TF ZEB1 (Supplementary Figure 4), thus validating our prediction that a strong EMT-inducing signal can give rise to M-CSCs instead of E/M-CSCs (see Figure 4D). Similar differences about levels of multiple epithelial and mesenchymal markers were reported in subsets of breast CSCs with varied EMT phenotypes E/M (ALDH+) and M (CD44+ CD24-) [36]. Furthermore, CSCs from breast cancer (MCF7), thyroid cancer, and glioblastoma were classified as hybrid E/M, epithelial, and mesenchymal respectively, highlighting the significant heterogeneity in EMT status of CSCs isolated from varying cancer types (Figure 5). This heterogeneity is also reflected via analyzing the data from spheres formed by colorectal cells (H29), glioma cells, and by heterogeneous HMLER cells. Finally, the side-population in pancreatic adenocarcinoma that express many CSC genes was predominantly hybrid E/M (Figure 5). Put together, these strongly suggest that while stem-like properties are most likely to be associated with a hybrid E/M phenotype, in accordance with our modeling prediction, the possibility of epithelial or mesenchymal subsets of CSCs is not ruled out. We further compared the level of Notch signaling in the CSCs with the non-stem cells (control) as quantified by a 10-genes 'Notch signature' [38]. In 7 out of 8 cases, with the exclusion of human glioblastoma cells (GSE20736), Notch signaling was more active in CSCs subpopulation, hence confirming that Notch activation may foster stemlike traits (Supplementary Figure 5). It is worth pointing out that since the datasets used here for CSCs are from a cell population instead of single-cell, a hybrid E/M phenotype prediction may correspond to bona fide hybrid $\mathrm{E} / \mathrm{M}$ cells and/or a mixture of $\mathrm{E}$ and $\mathrm{M}$ cells.

\section{Metformin restricts the existence of coupled E/M- D/U- S/R state}

To further test the ability of our computational model in recapitulating experimental observations, we modeled the effect of metformin in decreasing tumor aggressiveness and targeting CSCs. Metformin, the most widely used antidiabetic drug, is recently receiving attention as an anticancer drug in the context of several cancer types, including prostate, breast, lung, and pancreatic cancer [39, 40]. Among other observed effects, it selectively targets CSCs growth [41, 42] via antagonizing LIN-28 [43], decreases EMT and cell invasiveness in melanoma [44], inhibits TGF-beta induced 
EMT in cervical carcinoma cells [27], and reduces metastases in mice models [42]. The assessment of the effect of Metformin can in the future be applied other drug treatments that couple to the basic elements of our circuit.

We integrated metformin into our mathematical model as an inhibitor of SNAIL and LIN-28 to consider the EMT-halting and CSC targeting effects, respectively $[27,43]$ (see Methods), and re-computed the $\left(I_{E X T}, \mathrm{NF}-\kappa \mathrm{B}\right)$ phase diagram shown in Figure 4.

We find that in presence of metformin, the (high Notch, high Jagged), i.e. hybrid S/R phenotype is accessible only under a strong EMT induction (Figure 6A). This result is consistent with the decrease in Notch1 levels in metformin-treated pancreatic cancer cells [26]. Metformin also acts as an EMT brake by inhibiting SNAIL, therefore demanding a stronger EMT push to achieve a hybrid E/M state (Figure 6B). This finding agrees well with its halting effect on TGF-beta induced EMT [27]. At low levels of EMT inducing signals, the cell is epithelial (E) and Notch signaling is therefore strongly inhibited via posttranslational regulation of Notch signaling components by microRNAs miR-34 and miR-200. Thus, the effect of metformin on Notch levels can be explained through the coupling between Notch and EMT modules. Furthermore, under the effect of metformin, the cell attains a DOWN/UP, i.e. stem-like phenotype only at very strong EMT induction and NF- $\kappa \mathrm{B}$ overexpression (Figure $6 \mathrm{C}$ ). In other words, our model predicts that metformin treatment pushes a large fraction of cells outside the 'stemness window', a prediction which is consistent with its effect in targeting CSC via LIN28. Combining these results shows that metformin severely restricts the coupled 'E/M- D/U- S/R' phenotype; this state is rescued only under a very strong EMT induction and NF$\kappa \mathrm{B}$ overexpression (Figure 6D).
A

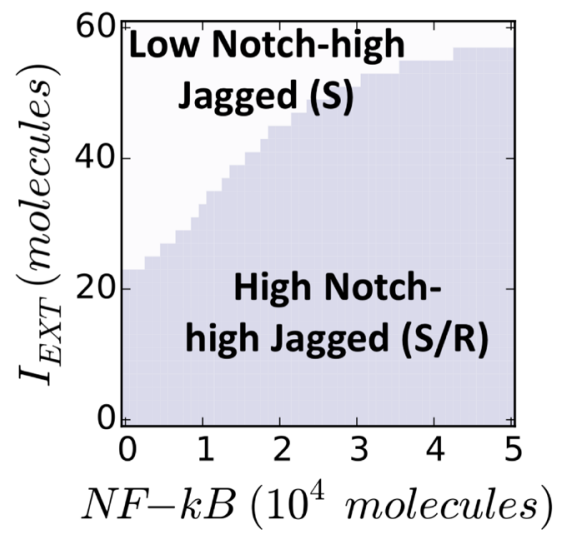

C

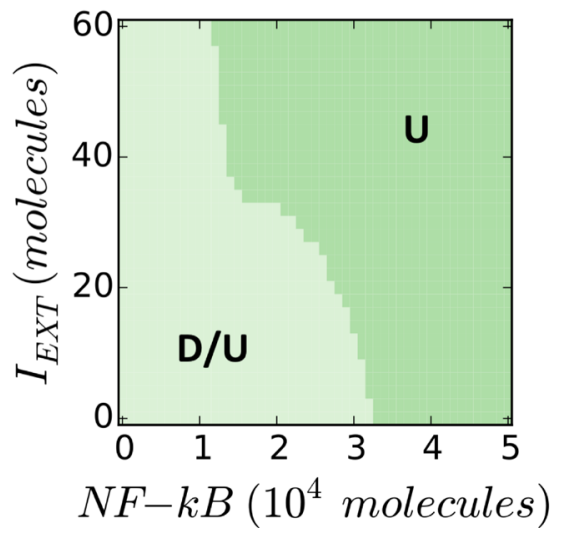

B

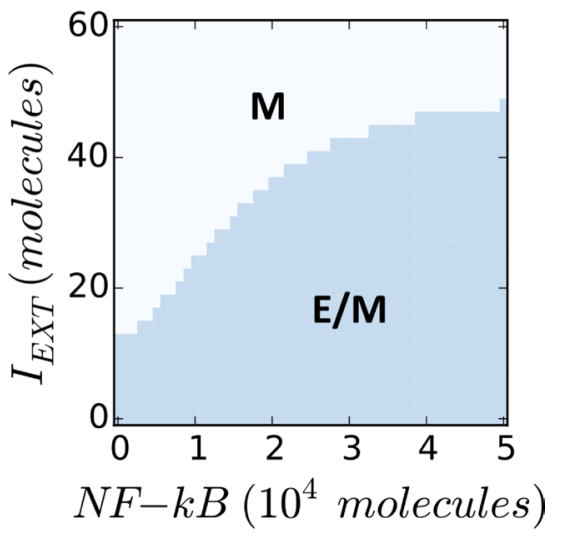

D

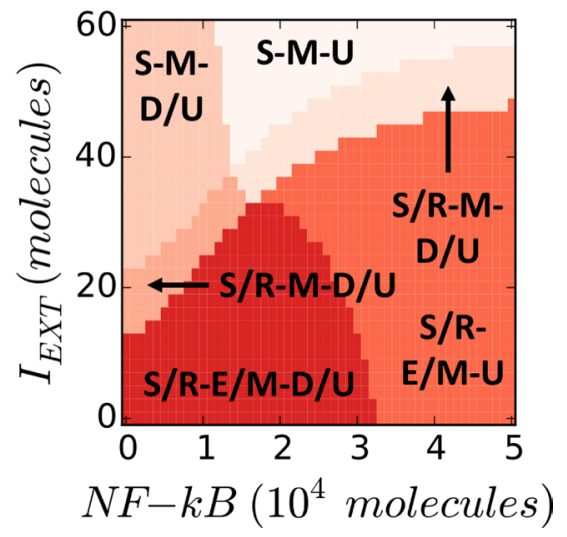

Figure 4: EMT Induction and NF- $\mathrm{B}$ overexpression push cancer cells out of the "S/R-E/M-D/U window". (A) Phenotypic characterization diagram of the Notch phenotype in presence of variable NF- $\mathrm{B}$ (x-axis) and EMT-Inducer $I_{E X T}$ (y-axis). A high $I_{E X T}$ pushes the cell out of the (high Notch, high Jagged) S/R phenotype, while NF- $\kappa \mathrm{B}$ increases the $I_{E X T}$ threshold needed to exit the S/R phenotype. (B) State diagram of the EMT state. The cell transitions from hybrid (E/M) to mesenchymal (M) when $I_{E X T}$ is increased, while $\mathrm{NF}-\kappa \mathrm{B}$ increases the $I_{E X T}$ threshold required for the transition. (C) Phenotypic characterization diagram of the Stem phenotype. The cell

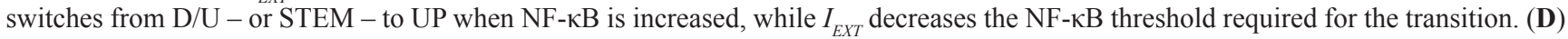
Overlap of the three maps highlights the S/R-E/M-D/U window. A large $I_{E X T}$ and/or overexpression of NF- $\kappa \mathrm{B}$ pushes the cell out of the window. In this simulation, the cell phenotype is measured upon full equilibration. The initial condition is always within the $\mathrm{S} / \mathrm{R}-\mathrm{E} / \mathrm{M}-\mathrm{D} / \mathrm{U}$ window. $L_{E X T}$ is constant at 2000 molecules and the EMT-STEM coupling is intermediate $\left(\lambda_{\text {LIM-28 }}=\lambda_{\text {ZEM-28 }}=0.5\right)$. 


\section{DISCUSSION}

We introduced a mechanism-based mathematical framework to investigate the interplay between epithelialmesenchymal transition (EMT), cancer stem cells (CSCs) and Notch signaling - three key axes contributing to cancer metastases and therapeutic resistance $[4,18,45]$.

Our model suggests a strong correlation between a hybrid E/M phenotype with CSC properties and augmented Notch-Jagged signaling. Such finding resonates well with the increasing evidence indicating that the higher plasticity and multi-lineage differentiation potential are more likely to be found midway en route to EMT - and not towards the mesenchymal end [46-48]. Furthermore, the predicted hybrid E/M stem-like state associates with reinforced Notch-Jagged signaling that (a) promotes resistance against chemo- and radio-therapy, (b) facilitates colonization by promoting cellcell communication between the cancer cells and the cells of the organ where they extravasate, as seen during bone metastases of breast cancer [49], and (c) coordinates spatial co-localization of hybrid E/M cells in the tumor tissue, hence facilitating the formation of clusters of hybrid $\mathrm{E} / \mathrm{M}$ cells [4]. Furthermore, Jagged1 - both in its transmembrane form (present on the cell surface) and soluble form (secreted by stromal endothelial cells) - appear to be a potent inducer of Notch signaling in maintaining and expanding the CSC population $[19,20]$. Consequently, Jagged1 levels are overexpressed in CSCs as compared to non-CSCs [50, 51], and are associated with poor survival and recurrence [18]. Overall, these findings support the increasingly accepted notion that a hybrid E/M state - and not necessarily a completely mesenchymal $\mathrm{M}$ state - should be considered as a hallmark of cancer aggressiveness [52, 53].

We further predict that while the 'stemness window' is most likely to lie midway along the 'EMT axis', various external signals and/or varying strengths of interactions among the Notch, EMT and STEM modules may shift the window along the axis. This prediction is supported by our analysis of gene expression profiles of CSCs belonging to different cancer subtypes, and report the presence of epithelial, hybrid E/M and mesenchymal CSCs. Recent experimental studies have identified such heterogeneity in EMT status of different CSCs across cancer subtypes [10, 12, $35,54-59]$, supporting the idea about a dynamic 'stemness window' [13] along the 'EMT axis'. Moreover, a recent clinical study identified different subsets of CTCs - those that expressed EMT markers but not stemness ones, those that expressed stemness markers but not EMT, those that

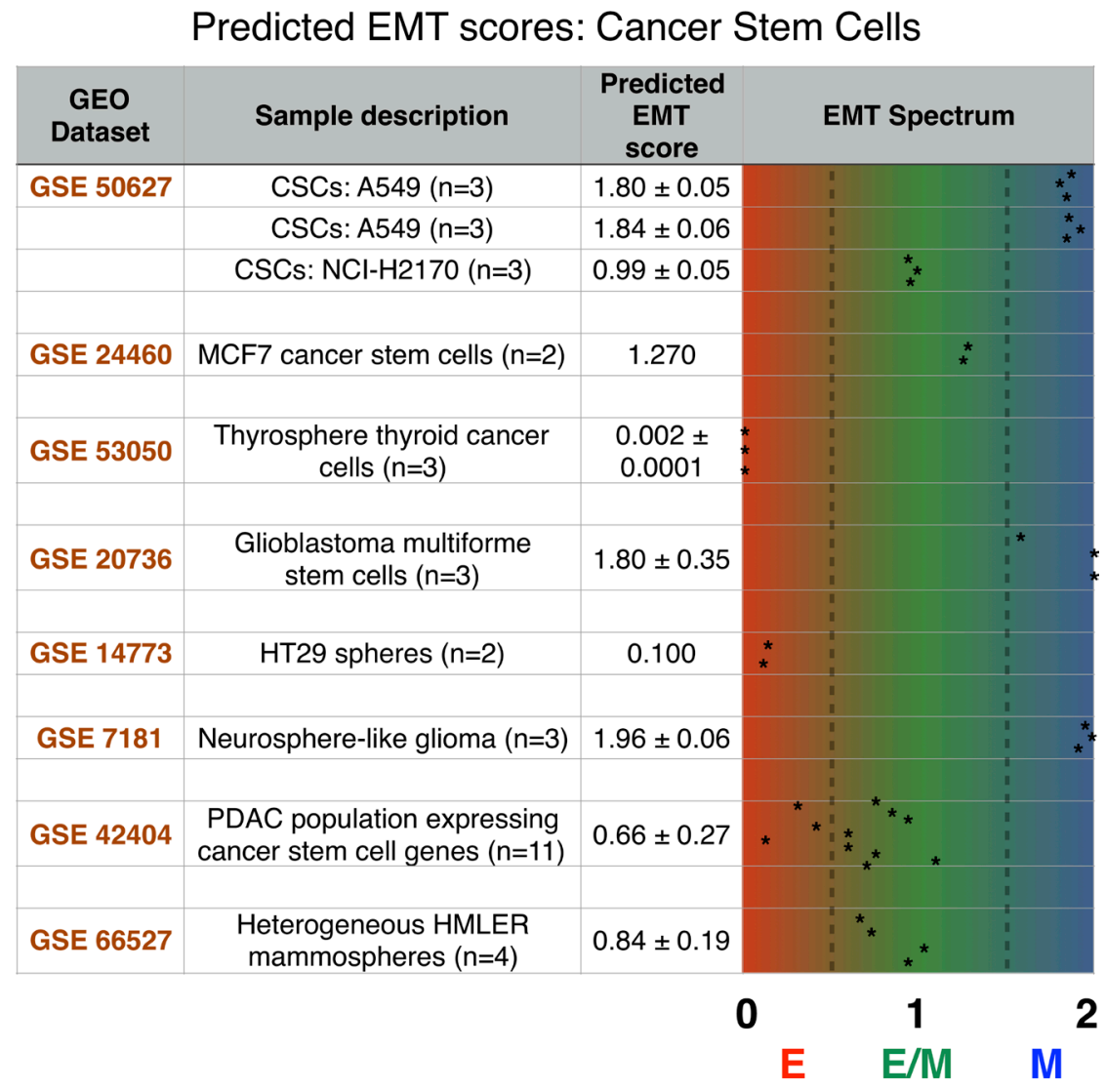

Figure 5: The predicted EMT score for several stem cancer subtypes shows a heterogeneous distribution across the EMT axis. Each dataset is identified by its GEO number. The number of each sample in a given dataset along with a brief explanation is provided in sample description. Mean and, when applicable, standard deviation for relevant samples in each dataset are reported in the predicted EMT score category, and individual samples are graphed on the EMT spectrum to illustrate sample heterogeneity. 
expressed both EMT and stemness markers, and those that expressed neither. The relative frequencies of these subsets changed upon neoadjuvant chemotherapy [57]. Put together, these observations display the importance of context-specific factors in modulating the phenotype of a cancer cell on the EMT and stemness axes $[60,61]$, including therapy-induced adaptive phenotypic transitions [62]. For instance, micro environmental factors such as inflammation and hypoxia can activate EMT and therefore reinforce a CSC phenotype [46]. Further, Notch ligands from neighboring cells (juxtacrine) or in soluble form (paracrine) can enhance the activation of Notch signaling, thereby boosting drug resistance, activating EMT and promoting CSCs [20,63]. Indeed, human breast stem cells co-expressing various epithelial and mesenchymal markers, as identified by single-cell RNA-seq, exhibited enriched Notch signaling. Consistently, Notch3 was found to be overexpressed in highly aggressive triple negative breast cancer samples and correlated with poor patient survival [36].

Previous mathematical models and experimental studies have identified multiple phenotypic stability factors (PSF) that can stabilize a hybrid E/M phenotype such as OVOL1/2 [64-66], GRHL2 [67], $\triangle \mathrm{NP63} \alpha$ [68], and NUMB/NUMBL [69] and facilitate collective cell migration. GRLH2 and OVOL1/2 directly target the miR-200-ZEB axis regulating EMT [64, 67], while NUMB/NUMBL modulates EMT via Notch-Jagged signaling [69]. Higher levels of these PSFs can also correlate with poor patient outcome [70]. Thus, future studies should investigate the effects of these and other PSFs in regulating cancer cell aggressiveness in vitro and in vivo to further elevate our understanding of the connection between EMT and stemness, and might potentially provide novel therapeutic targets to break the clusters of circulating tumor cells (CTCs) driving metastases.

Lastly, the model recapitulates the effect of metformin, a drug capable of inhibiting EMT and selectively targeting CSCs [27, 41]. Its effect can be interpreted in terms of restricting the existence of a coupled 'S/R - E/M - D/U' state. In particular, reversing a partial EMT naturally restricts the Notch-Jagged signaling axis [26], while overexpressing NF- $\mathrm{NB}$ recovers stem-like traits
A

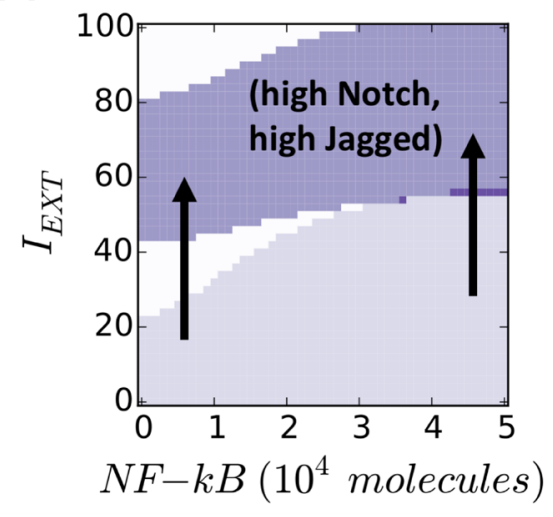

$\mathrm{C}$

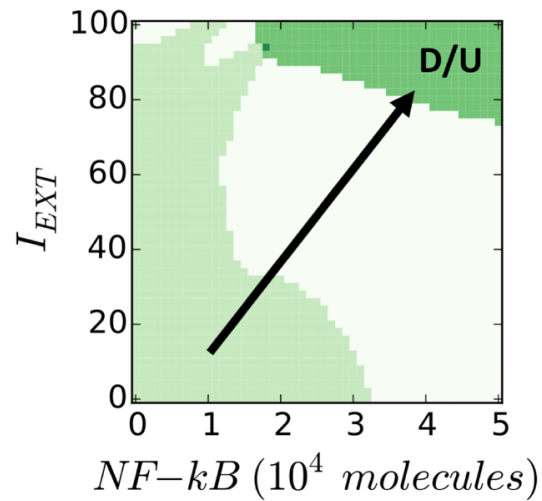

B

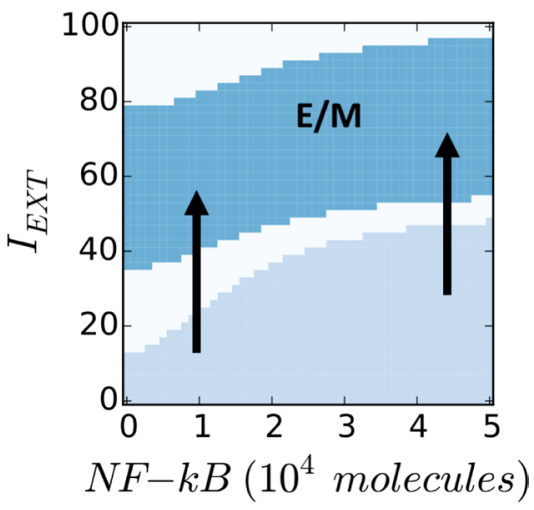

D

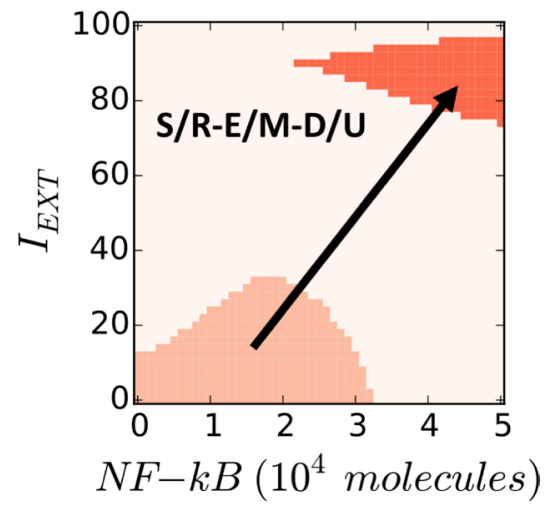

Figure 6: Metformin restricts the existence of coupled E/M- D/U- S/R state. (A) The (high Notch, high Jagged) region is shifted to higher levels of external EMT-inducer $I_{E X T}$ in presence of metformin (dark purple) compared to the control (i.e. no metformin) case (light purple). (B) The hybrid E/M EMT state is shifted to higher levels of external EMT-inducer $I_{E X T}$ in presence of metformin (dark blue) compared to the control case (light blue). (C) The D/U STEM phenotype is pushed to (high EMT-inducer, high NF- $\mathrm{BB}$ ) in presence of metformin compared to the control case (dark green vs light green). (D) Metformin enables the existence of a coupled ' $\mathrm{E} / \mathrm{M}-\mathrm{D} / \mathrm{U}-\mathrm{S} / \mathrm{R}$ ' state only at (high EMT-inducer, high $\mathrm{NF}-\kappa \mathrm{B}$ ) levels (dark orange), as compared to the control case where the 'E/M- D/U- S/R' state can exist at (low EMT inducer, low NF- $\mathrm{B}$ ) levels (light orange). For this simulation, $L_{E X T}=2000$ molecules and the EMT-STEM coupling is intermediate $\left(\lambda_{L I M-28}=\lambda_{Z E M}=0.5\right)$. 
via activation of LIN-28 inhibited by metformin [28]. While it is beyond the scope of the current model to comment on context-specific factors that could affect metformin action in different tumor types, this result suggests that metformin could achieve its maximal effect when the connections among the different considered tumor hallmarks (e.g. EMT, stemness, and Notch activation) is stronger.

Therefore, our model provides a mechanismbased explanation for otherwise uncorrelated biological observations among Notch, EMT and stem-like traits, and offers a predictive platform towards gaining an integrative, functional, mechanism-based understanding of cancer metastases.

\section{MATERIALS AND METHODS}

\section{Notch module}

The level of Notch receptor (N), Delta (D) Jagged (J) and NICD (I) in the cell are modeled via a system of ordinary differential equations according to the model of Boareto et al. [24, 71]:

(1a) $\frac{d N}{d t}=k_{P} g_{N} H^{S+}(I) P_{l}\left(\mu_{34}, n_{N}\right)-N\left[\left(k_{c} D+k_{c} J\right)+\left[\left(k_{t} D_{e x t}+\left(k_{t} J_{\text {ext }}\right)\right]-\gamma N\right.\right.$

(1b) $\frac{d D}{d t}=k_{P} g_{D} H^{S-}(I) P_{l}\left(\mu_{34}, n_{D}\right)-D\left(k_{c} N+k_{t} N_{e x t}\right)-\gamma D$

(1c) $\frac{d J}{d t}=k_{P} g_{J} H^{S+}(I) P_{l}\left(\mu_{200}, n_{J}\right)-J\left(k_{c} N+k_{t} N_{e x t}\right)-\gamma J$

(1d) $\frac{d I}{d t}=N\left(k_{t} D_{e x t}+k_{t} J_{e x t}\right)-\gamma_{I} I$

with transcription rates $g_{N}, g_{D}, g_{J}$ for Notch, Delta and Jagged mRNA (not explicitly present in the model) and translation rate $k_{P}$. Notch, Delta and Jagged degrade at rate $\gamma$, while NICD has a faster rate $\gamma_{r}$. The functions $H^{S+}(I) / H^{S-}(I)$ indicate positive/negative transcriptional regulation of NICD activating Notch, Jagged and inhibiting Delta (see Supplementary Information section "Mathematical modeling of transcriptional/translational interactions" for details). The function $P_{l}(\mu, n)$ models the post-translational inhibition exerted by micro-RNA $\mu$ (miR-34 or miR-200) binding on the $n$ binding domains on Notch, Delta or Jagged. These terms therefore represent the connection between EMT and Notch modules (see Supplementary Information section "Mathematical modeling of post-translational interactions" for details). $k_{c}$ and $k_{i}$ are the receptor-ligand binding constants for cisinteraction (receptor and ligand from same cell leading to complex degradation) and trans-interaction (native receptor binding with external ligand leading to NICD release). $N_{e x t}, D_{e x t}$ and $J_{e x t}$ are the amount of external Notch, Delta and Jagged at cell surface available to bind with the cell's receptors and ligands. The parameter values for the Notch circuit are presented in the Supplementary Table 1.

The phenotypes expressed by the Notch module are based on the levels of Notch receptor and Jagged ligand. We introduce thresholds for the Notch receptor $(\mathrm{N} \sim 13000$ receptor molecules) and the Jagged ligand ( $\sim 350$ ligand molecules) such that the (high Notch, high Jagged) hybrid Sender-Receiver $(\mathrm{S} / \mathrm{R})$ phenotype satisfies (Notch $>\mathrm{N}$, Jagged $>\mathrm{J}$ ). If (Notch $<\mathrm{N}$, Jagged $>\mathrm{J}$ ) the cell is a (low Notch, high Jagged) Sender (S) cell, while if (Notch $>N$, Jagged $<\mathrm{J}$ ) the cell is a (high Notch, low Jagged) Receiver (R) cell. In principle, an inactive (Notch $<\mathrm{N}$, Jagged $<\mathrm{J}$ ) phenotype should also be considered but is never observed for the chosen values of N, J. Previous modeling on the Notch-Delta-Jagged system by Boareto et al. [24, 71] defined the Notch phenotypes based on the branches of a bifurcation diagram, similar to the current definition of the EMT states. Therefore, our model does not classify the Notch phenotypes in the same way but maintains the same terminology (Sender, Receiver, hybrid Sender/Receiver).

\section{EMT module}

The interactions between miR-34 $\left(\mu_{34}\right)$, miR-200 $\left(\mu_{200}\right)$, ZEB $(Z)$ and SNAIL (S) depicted in Figure 1B are modeled via a system of ordinary differential equations according to Lu et al. [72]:

$$
\begin{aligned}
& (2 a) \frac{d \mu_{34}}{d t}=g_{\mu_{34}} H^{S}(S) H^{S}(Z)-g_{S} H^{S}(S) H^{S+}(I) H^{S+}\left(I_{e x t}\right) P_{y}\left(\mu_{34}, 2\right)-\gamma_{\mu_{3}} \mu_{34} \\
& (2 b) \frac{d \mu_{200}}{d t}=g_{\mu_{200}} H^{S}(Z) H^{S}(S)-g_{Z} H^{S}(Z) H^{S}(S) P_{y}\left(\mu_{200}, 6\right)-\gamma_{\mu_{200}} \mu_{200} \\
& (2 c) \frac{d Z}{d t}=k_{P} g_{Z} H^{S}(Z) H^{S}(S) H^{S-}\left(L_{7}\right) P_{l}\left(\mu_{200}, 6\right)-\gamma_{Z} Z \\
& (2 d) \frac{d S}{d t}=k_{P} g_{S} H^{S}(S) H^{S+}(I) H^{S+}\left(I_{e x t}\right) P_{l}\left(\mu_{34}, 2\right)-\gamma_{S} S
\end{aligned}
$$

with basal transcription rates $g_{\mu 200}, g_{\mu 34}, g_{\mathrm{Z}}, g_{\mathrm{s}}$, translation rate $k_{P}$ and degradation rates $\gamma_{\mu 200}, \gamma_{\mu 34}, \gamma_{\mathrm{Z}}, \gamma_{\mathrm{s}}$. Similar to the Notch module, the functions $H^{S+}(I) / H^{S-}(I)$ model transcription/translational interactions of ZEB and SNAIL while the function $P_{l}(\mu, n)$ represents posttranslational inhibition of SNAIL and ZEB by miR-34 and miR-200, respectively. The corresponding loss of miR-34 and miR-200 due to micro-RNA-protein complex degradation is modeled via the associate function $P_{y}(\mu, n)$ (see Supplementary Information section "Mathematical modeling of post-translational interactions" for details). The term $H^{S+}(I)$ represents transcriptional activation of SNAIL by NICD, and therefore connects the Notch and EMT modules. Additionally, the term $H^{S-}\left(L_{7}\right)$ models the inhibition of ZEB by Let-7, thereby connecting Stem and EMT modules. The effect of an external EMT inducer $I_{\text {ext }}$ is considered via the shifted Hill function $H^{S-}\left(I_{\text {ext }}\right)$ activating SNAIL. The parameter values for the EMT circuit are presented in the Supplementary Tables 2-3.

The EMT states (epithelial, hybrid E/M, mesenchymal) are defined based on the levels of microRNA miR-200 (epithelial: miR-200 > 15000 molecules; hybrid E/M: 5000 molecules $<$ miR-200 < 15000 molecules; mesenchymal: miR-200 $<5000$ molecules). This definition reflects the mathematical solutions, or branches, of the bifurcation diagram of Figure 2A, and was already used in 
the original work by Lu et al. [72] that introduced the EMT module.

\section{Stem module}

The stem circuit of Figure $1 \mathrm{C}$ including LIN-28 $\left(L_{28}\right)$ and Let-7 $\left(L_{7}\right)$ is described by the model of Jolly et al. [13]:

(3a) $\frac{d L_{28}}{d t}=g_{L_{28}} H^{S-}\left(\mu_{200}\right) H^{S+}\left(L_{28}\right) H^{S-}\left(L_{7}\right) H^{S+}(N F-k B)-\gamma_{L_{28}} L_{28}$

(3b) $\frac{d L_{7}}{d t}=g_{L_{7}} H^{S+}\left(L_{7}\right) H^{S-}\left(L_{28}\right) H^{S+}(N F-k B)-\gamma_{L_{7}} L_{7}$

Where $g_{L 28}$ and $g_{L 7}$ are production rates and $\gamma_{L 28}$ and $\gamma_{L 7}$ are degradation rates. In the genetic circuit, LIN-28 selfactivates $\left(H^{S^{+}}\left(L_{28}\right)\right)$ and inhibits Let-7 $\left(H^{S-}\left(L_{7}\right)\right)$. Similarly, Let-7 activates itself $\left(H^{S+}\left(L_{7}\right)\right)$ and represses the expression of LIN-28 $\left(H^{S-}\left(L_{28}\right)\right)$ resulting in the double negative switch. The stem module is connected to the EMT module via the term $H^{S}\left(\mu_{200}\right)$ describing inhibition of LIN-28 by miR-200. Finally, $H^{S+}(N F-k B)$ represents the effect of NF- $\kappa \mathrm{B}$ signaling activating LIN-28 and Let-7. The parameter values for the STEM circuit are presented in the Supplementary Table 4.

The stem interval (as shown in Figure 2B) is defined as follow. We considered the extremal values assumed by LIN-28 (the minimum $\mathrm{m}$ at $L_{\text {ext }}=0$ molecules and the maximal $\mathrm{M}$ at $L_{e x t}=10000$ molecules) and defined the window as $[\mathrm{m}+0.25(\mathrm{M}-\mathrm{m}), \mathrm{m}+0.65(\mathrm{M}-\mathrm{m})][13,15]$. Based on the diagram of Figure $2 \mathrm{~B}, m \sim 56000$ molecules, $M \sim 110000$ molecules. Therefore, the cell is DOWN for LIN-28 $<\mathrm{m}$, DOWN/UP for $\mathrm{m}<\mathrm{LIN}-28<\mathrm{M}$, and UP for LIN-28 $>$ M. The motivation for this classification is that an intermediate expression level of OCT4, a direct target of LIN-28, has been associated with stem-like traits [13].

\section{Modeling metformin treatment}

We modelled the effect of Metformin on the coupled Notch-EMT-stemness circuit via shifted Hill functions [72] that negatively modulate the production rate of SNAIL and LIN-28 as:

$$
\begin{aligned}
& (4 a) g_{S} \stackrel{\text { Metformin }}{\rightarrow} g_{S} H^{S-}(M) \\
& (4 b) g_{L_{28}} \stackrel{\text { Metformin }}{\rightarrow} g_{L_{28}} H^{S-}(M)
\end{aligned}
$$

Where $\mathrm{M}$ represent a constant level or intensity of metformin treatment. We are not conducting a detailed dose-response analysis here, thus, including metformin effectively results in a decrease in production rates for SNAIL and LIN-28. The parameters corresponding to the effect of metformin have been chosen empirically, and are considered to be the same for both LIN-28 and SNAIL (Supplementary Table 5). Detailed time-course and dose-response experiments investigating the effects of metformin in multiple cancer types can provide more reliable parameters for these interactions that can be then incorporated into this modeling framework.

\section{Numerical calculation details}

We developed all source code in Python and used the numerical library PyDSTool [73] to compute the bifurcation diagrams. All plotting was performed using the Python numerical library Matplotlib [74].

\section{EMT score quantification}

The EMT Metric previously described [37] was applied to various Gene Expression Omnibus (GEO) datasets containing CSCs. A collection of EMT-relevant predictor transcripts as well as a cross-platform normalizer transcripts was extracted for each dataset and used to probabilistically categorize samples into an element of $\{\mathrm{E}$, $\mathrm{E} / \mathrm{M}, \mathrm{M}\}$. To each sample $\mathrm{i}$ there corresponds an ordered triple $\mathrm{S}_{\mathrm{i}}=\left(\mathrm{P}_{\mathrm{E}}, \mathrm{P}_{\mathrm{E} / \mathrm{M}}, \mathrm{P}_{\mathrm{M}}\right)$ that characterizes the probability of group membership. Categorization was assigned based on the maximal value of this ordered triple. $\mathrm{S}_{\mathrm{i}}$ was then projected onto $[0,2]$ by use of the EMT metric. The metric places epithelial (resp. mesenchymal) samples close to 0 (resp. 2) while maximally hybrid E/M samples are assigned values close to 1 .

\section{Author contributions}

FB and MKJ designed research, FB performed numerical calculations (Figure 2-4, 6), JG performed EMT score analysis (Figure 5), all authors discussed results and wrote the paper.

\section{CONFLICTS OF INTEREST}

The authors declare no conflicts of interest.

\section{FUNDING}

This work was sponsored by the National Science Foundation NSF grants PHY-1427654 (Center for Theoretical Biological Physics), PHY-1605817, CHE1614101, MCB-1241332 and by the Cancer Prevention and Research Institute of Texas (CPRIT-grant R1110). Federico Bocci is partially supported by the Hasselman Fellowship for academic excellence in Chemistry. MKJ is also supported by a training fellowship from the Gulf Coast Consortia, on the Computational Cancer Biology Training Program (CPRIT Grant No. RP170593).

\section{REFERENCES}

1. Gupta GP, Massagué J. Cancer metastasis: building a framework. Cell. 2006; 127:679-95. https://doi.org/10.1016/j. cell.2006.11.001.

2. Cheung KJ, Ewald AJ. A collective route to metastasis: seeding by tumor cell clusters. Science. 2016; 352:167-69. https://doi.org/10.1126/science.aaf6546. 
3. Fabisiewicz A, Grzybowska E. CTC clusters in cancer progression and metastasis. Med Oncol. 2017; 34:12. https://doi.org/10.1007/s12032-016-0875-0.

4. Jolly MK, Boareto M, Huang B, Jia D, Lu M, Ben-Jacob E, Onuchic JN, Levine H. Implications of the hybrid epithelial/ mesenchymal phenotype in metastasis. Front Oncol. 2015; 5:155. https://doi.org/10.3389/fonc.2015.00155.

5. Nieto MA, Huang RY, Jackson RA, Thiery JP. EMT: 2016. Cell. 2016; 166:21-45. https://doi.org/10.1016/j.cell.2016.06.028.

6. Jolly MK, Levine H. Computational systems biology of epithelial-hybrid-mesenchymal transitions. Curr Opin Syst Biol. 2017; 3:1-6. https://doi.org/10.1016/j.coisb.2017.02.004.

7. Burk U, Schubert J, Wellner U, Schmalhofer O, Vincan E, Spaderna S, Brabletz T. A reciprocal repression between ZEB1 and members of the miR-200 family promotes EMT and invasion in cancer cells. EMBO Rep. 2008; 9:582-89. https://doi.org/10.1038/embor.2008.74.

8. Siemens H, Jackstadt R, Hünten S, Kaller M, Menssen A, Götz U, Hermeking H. miR-34 and SNAIL form a doublenegative feedback loop to regulate epithelial-mesenchymal transitions. Cell Cycle. 2011; 10:4256-71. https://doi. org/10.4161/cc.10.24.18552.

9. Bracken CP, Gregory PA, Kolesnikoff N, Bert AG, Wang J, Shannon MF, Goodall GJ. A double-negative feedback loop between ZEB1-SIP1 and the microRNA-200 family regulates epithelial-mesenchymal transition. Cancer Res. 2008; 68:784654. https://doi.org/10.1158/0008-5472.CAN-08-1942.

10. Grosse-Wilde A, Fouquier d'Hérouël A, McIntosh E, Ertaylan G, Skupin A, Kuestner RE, del Sol A, Walters KA, Huang S. Stemness of the hybrid epithelial/mesenchymal state in breast cancer and its association with poor survival. PLoS One. 2015; 10:e126522. https://doi.org/10.1371/journal.pone.0126522.

11. Mani SA, Guo W, Liao MJ, Eaton EN, Ayyanan A, Zhou AY, Brooks M, Reinhard F, Zhang CC, Shipitsin M, Campbell LL, Polyak K, Brisken C, et al. The epithelial-mesenchymal transition generates cells with properties of stem cells. Cell. 2008; 133:704-15. https://doi.org/10.1016/j.cell.2008.03.027.

12. Celià-Terrassa T, Meca-Cortés O, Mateo F, Martínez de Paz A, Rubio N, Arnal-Estapé A, Ell BJ, Bermudo R, Díaz A, GuerraRebollo M, Lozano JJ, Estarás C, Ulloa C, et al. Epithelialmesenchymal transition can suppress major attributes of human epithelial tumor-initiating cells. J Clin Invest. 2012; 122:1849-68. https://doi.org/10.1172/JCI59218.

13. Jolly MK, Jia D, Boareto M, Mani SA, Pienta KJ, Ben-Jacob E, Levine H. Coupling the modules of EMT and stemness: A tunable 'stemness window' model. Oncotarget. 2015; 6:25161-74. https://doi.org/10.18632/oncotarget.4629.

14. Yang X, Lin X, Zhong X, Kaur S, Li N, Liang S, Lassus H, Wang L, Katsaros D, Montone K, Zhao X, Zhang Y, Bützow R, et al. Double-negative feedback loop between reprogramming factor LIN28 and microRNA let-7 regulates aldehyde dehydrogenase 1-positive cancer stem cells. Cancer Res. 2010; 70:9463-72. https://doi. org/10.1158/0008-5472.CAN-10-2388.
15. Jolly MK, Huang B, Lu M, Mani SA, Levine H, Ben-Jacob E. Towards elucidating the connection between epithelialmesenchymal transitions and stemness. J R Soc Interface. 2014; 11:20140962. https://doi.org/10.1098/rsif.2014.0962.

16. Karwacki-Neisius V, Göke J, Osorno R, Halbritter F, $\mathrm{Ng} \mathrm{JH}$, Weiße AY, Wong FC, Gagliardi A, Mullin NP, Festuccia N, Colby D, Tomlinson SR, Ng HH, Chambers I. Reduced Oct4 expression directs a robust pluripotent state with distinct signaling activity and increased enhancer occupancy by Oct4 and Nanog. Cell Stem Cell. 2013; 12:531-45. https://doi.org/10.1016/j.stem.2013.04.023.

17. Niwa H, Miyazaki J, Smith AG. Quantitative expression of OCT3/4 defines differentiation, dedifferentiation or selfrenewal of ES cells. Nat Genet. 2016; 24:2-6.

18. Li D, Masiero M, Banham AH, Harris AL. The notch ligand JAGGED1 as a target for anti-tumor therapy. Front Oncol. 2014; 4:254. https://doi.org/10.3389/fonc.2014.00254.

19. Yamamoto $M$, Taguchi $Y$, Ito-Kureha $T$, Semba $K$, Yamaguchi N, Inoue J. NF- $\mathrm{B}$ non-cell-autonomously regulates cancer stem cell populations in the basal-like breast cancer subtype. Nat Commun. 2013; 4:2299. https://doi.org/10.1038/ncomms3299.

20. Lu J, Ye X, Fan F, Xia L, Bhattacharya R, Bellister S, Tozzi F, Sceusi E, Zhou Y, Tachibana I, Maru DM, Hawke DH, Rak J, et al. Endothelial cells promote the colorectal cancer stem cell phenotype through a soluble form of Jagged-1. Cancer Cell. 2013; 23:171-85. https://doi.org/10.1016/j.ccr.2012.12.021.

21. Jolly MK, Boareto M, Debeb BG, Aceto N, Farach-Carson MC, Woodward WA, Levine H. Inflammatory breast cancer: a model for investigating cluster-based dissemination. NPJ Breast Cancer. 2017; 3:21. https://doi.org/10.1038/ s41523-017-0023-9.

22. Cheung KJ, Padmanaban V, Silvestri V, Schipper K, Cohen JD, Fairchild AN, Gorin MA, Verdone JE, Pienta KJ, Bader JS, Ewald AJ. Polyclonal breast cancer metastases arise from collective dissemination of keratin 14-expressing tumor cell clusters. Proc Natl Acad Sci U S A. 2016; 113:E854-63. https://doi.org/10.1073/pnas.1508541113.

23. Andersson ER, Sandberg R, Lendahl U. Notch signaling: simplicity in design, versatility in function. Development. 2011; 138:3593-612. https://doi.org/10.1242/dev.063610.

24. Boareto M, Jolly MK, Lu M, Onuchic JN, Clementi C, Ben-Jacob E. Jagged-Delta asymmetry in Notch signaling can give rise to a Sender/Receiver hybrid phenotype. Proc Natl Acad Sci U S A. 2015; 112:E402-09. https://doi. org/10.1073/pnas.1416287112.

25. Petrovic J, Formosa-Jordan P, Luna-Escalante JC, Abelló G, Ibañes M, Neves J, Giraldez F. Ligand-dependent Notch signaling strength orchestrates lateral induction and lateral inhibition in the developing inner ear. Development. 2014; 141:2313-24. https://doi.org/10.1242/dev.108100.

26. Bao B, Wang Z, Ali S, Ahmad A, Azmi AS, Sarkar SH, Banerjee S, Kong D, Li Y, Thakur S, Sarkar FH. Metformin inhibits cell proliferation, migration and invasion by 
attenuating CSC function mediated by deregulating miRNAs in pancreatic cancer cells. Cancer Prev Res (Phila). 2012; 5:355-64. https://doi.org/10.1158/1940-6207. CAPR-11-0299.

27. Cheng K, Hao M. Metformin inhibits TGF- $\beta 1$-induced epithelial-to-mesenchymal transition via PKM2 relative$\mathrm{mTOR} / \mathrm{p} 70 \mathrm{~s} 6 \mathrm{k}$ signaling pathway in cervical carcinoma cells. Int J Mol Sci. 2016; 17. https://doi.org/10.3390/ijms17122000.

28. Zheng L, Yang W, Wu F, Wang C, Yu L, Tang L, Qiu B, Li Y, Guo L, Wu M, Feng G, Zou D, Wang H. Prognostic significance of AMPK activation and therapeutic effects of metformin in hepatocellular carcinoma. Clin Cancer Res. 2013; 19:5372-80. https://doi.org/10.1158/1078-0432.CCR-13-0203.

29. Sahlgren C, Gustafsson MV, Jin S, Poellinger L, Lendahl $\mathrm{U}$. Notch signaling mediates hypoxia-induced tumor cell migration and invasion. Proc Natl Acad Sci U S A. 2008; 105:6392-97. https://doi.org/10.1073/pnas.0802047105.

30. Niessen K, Fu Y, Chang L, Hoodless PA, McFadden $\mathrm{D}$, Karsan A. Slug is a direct Notch target required for initiation of cardiac cushion cellularization. J Cell Biol. 2008; 182:315-25. https://doi.org/10.1083/jcb.200710067.

31. Brabletz S, Bajdak K, Meidhof S, Burk U, Niedermann G, Firat E, Wellner U, Dimmler A, Faller G, Schubert J, Brabletz T. The ZEB1/miR-200 feedback loop controls Notch signalling in cancer cells. EMBO J. 2011; 30:770-82. https://doi.org/10.1038/emboj.2010.349.

32. de Antonellis P, Medaglia C, Cusanelli E, Andolfo I, Liguori L, De Vita G, Carotenuto M, Bello A, Formiggini F, Galeone A, De Rosa G, Virgilio A, Scognamiglio I, et al. MiR-34a targeting of Notch ligand delta-like 1 impairs CD15+/CD133+ tumor-propagating cells and supports neural differentiation in medulloblastoma. PLoS One. 2011; 6:e24584. https://doi.org/10.1371/journal.pone.0024584.

33. Bu P, Chen KY, Chen JH, Wang L, Walters J, Shin YJ, Goerger JP, Sun J, Witherspoon M, Rakhilin N, Li J, Yang H, Milsom J, et al. A microRNA miR-34a-regulated bimodal switch targets Notch in colon cancer stem cells. Cell Stem Cell. 2013; 12:602-15. https://doi.org/10.1016/j. stem.2013.03.002.

34. Krebs AM, Mitschke J, Lasierra Losada M, Schmalhofer O, Boerries M, Busch H, Boettcher M, Mougiakakos D, Reichardt W, Bronsert P, Brunton VG, Pilarsky C, Winkler $\mathrm{TH}$, et al. The EMT-activator Zeb1 is a key factor for cell plasticity and promotes metastasis in pancreatic cancer. Nat Cell Biol. 2017; 19:518-29. https://doi.org/10.1038/ncb3513.

35. Liu S, Cong Y, Wang D, Sun Y, Deng L, Liu Y, MartinTrevino R, Shang L, McDermott SP, Landis MD, Hong S, Adams A, D'Angelo R, et al. Breast cancer stem cells transition between epithelial and mesenchymal states reflective of their normal counterparts. Stem Cell Reports. 2013; 2:78-91. https://doi.org/10.1016/j.stemcr.2013.11.009.

36. Colacino JA, Azizi E, Brooks MD, Harouaka R, Fouladdel S, McDermott SP, Lee M, Hill D, Madden J, Boerner J, Cote ML, Sartor MA, Rozek LS, et al. Heterogeneity of
Human Breast Stem and Progenitor Cells as Revealed by Transcriptional Profiling. Stem Cell Reports. 2018; 10:15961609. https://doi.org/10.1016/j.stemcr.2018.03.001.

37. George JT, Jolly MK, Xu S, Somarelli JA, Levine H. Survival Outcomes in Cancer Patients Predicted by a Partial EMT Gene Expression Scoring Metric. Cancer Res. 2017; 77:6415-28. https://doi.org/10.1158/0008-5472.CAN-16-3521.

38. Chen F, Liu N. A 10-gene expression signature of Notch pathway predicts recurrence in ovarian carcinoma. Oncol Lett. 2015; 10:1704-08. https://doi.org/10.3892/ol.2015.3382.

39. Ben Sahra I, Le Marchand-Brustel Y, Tanti JF, Bost F. Metformin in cancer therapy: a new perspective for an old antidiabetic drug? Mol Cancer Ther. 2010; 9:1092-99. https://doi.org/10.1158/1535-7163.MCT-09-1186.

40. Pollak M. Metformin and other biguanides in oncology: advancing the research agenda. Cancer Prev Res (Phila). 2010; 3:1060-65. https://doi.org/10.1158/1940-6207. CAPR-10-0175.

41. Hirsch HA, Iliopoulos D, Tsichlis PN, Struhl K. Metformin selectively targets cancer stem cells, and acts together with chemotherapy to block tumor growth and prolong remission. Cancer Res. 2009; 69:7507-11. https://doi. org/10.1158/0008-5472.CAN-09-2994.

42. Hirsch HA, Iliopoulos D, Struhl K. Metformin inhibits the inflammatory response associated with cellular transformation and cancer stem cell growth. Proc Natl Acad Sci U S A. 2013; 110:972-77. https://doi.org/10.1073/ pnas. 1221055110.

43. McCarty MF. Metformin may antagonize Lin28 and/ or Lin28B activity, thereby boosting let-7 levels and antagonizing cancer progression. Med Hypotheses. 2012; 78:262-69. https://doi.org/10.1016/j.mehy.2011.10.041.

44. Tomic T, Botton T, Cerezo M, Robert G, Luciano F, Puissant A, Gounon P, Allegra M, Bertolotto C, Bereder JM, TartareDeckert S, Bahadoran P, Auberger P, et al. Metformin inhibits melanoma development through autophagy and apoptosis mechanisms. Cell Death Dis. 2011; 2:e199-10. https://doi.org/10.1038/cddis.2011.86.

45. May CD, Sphyris N, Evans KW, Werden SJ, Guo W, Mani SA. Epithelial-mesenchymal transition and cancer stem cells: a dangerously dynamic duo in breast cancer progression. Breast Cancer Res. 2011; 13:202. https://doi. org/10.1186/bcr2789.

46. Shibue T, Weinberg RA. EMT, CSCs, and drug resistance: the mechanistic link and clinical implications. Nat Rev Clin Oncol. 2017; 14:611-629. https://doi.org/10.1038/ nrclinonc.2017.44.

47. Varga J, Greten FR. Cell plasticity in epithelial homeostasis and tumorigenesis. Nat Cell Biol. 2017; 19:1133-41. https:// doi.org/10.1038/ncb3611.

48. Pastushenko I, Brisebarre A, Sifrim A, Fioramonti M, Revenco T, Boumahdi S, Van Keymeulen A, Brown D, Moers V, Lemaire S, De Clercq S, Minguijón E, Balsat C, et al. Identification of the tumour transition states occurring 
during EMT. Nature. 2018; 556:463-68. https://doi. org/10.1038/s41586-018-0040-3.

49. Sethi N, Dai X, Winter CG, Kang Y. Tumor-derived JAGGED1 promotes osteolytic bone metastasis of breast cancer by engaging notch signaling in bone cells. Cancer Cell. 2011; 19:192-205. https://doi.org/10.1016/j. ccr.2010.12.022.

50. Wang Z, Li Y, Kong D, Banerjee S, Ahmad A, Azmi AS, Ali S, Abbruzzese JL, Gallick GE, Sarkar FH. Acquisition of epithelial-mesenchymal transition phenotype of gemcitabineresistant pancreatic cancer cells is linked with activation of the notch signaling pathway. Cancer Res. 2009; 69:2400-07. https://doi.org/10.1158/0008-5472.CAN-08-4312.

51. Sansone P, Storci G, Tavolari S, Guarnieri T, Giovannini C, Taffurelli M, Ceccarelli C, Santini D, Paterini P, Marcu KB, Chieco P, Bonafè M. IL-6 triggers malignant features in mammospheres from human ductal breast carcinoma and normal mammary gland. J Clin Invest. 2007; 117:39884002. https://doi.org/10.1172/JCI32533.

52. Celià-Terrassa T, Kang Y. Distinctive properties of metastasis-initiating cells. Genes Dev. 2016; 30:892-908. https://doi.org/10.1101/gad.277681.116.

53. Bierie B, Pierce SE, Kroeger C, Stover DG, Pattabiraman DR, Thiru P, Liu Donaher J, Reinhardt F, Chaffer CL, Keckesova Z, Weinberg RA. Integrin- $\beta 4$ identifies cancer stem cell-enriched populations of partially mesenchymal carcinoma cells. Proc Natl Acad Sci U S A. 2017; 114:E2337-46. https://doi.org/10.1073/pnas.1618298114.

54. Beerling E, Seinstra D, de Wit E, Kester L, van der Velden D, Maynard C, Schäfer R, van Diest P, Voest E, van Oudenaarden A, Vrisekoop N, van Rheenen J. Plasticity between Epithelial and Mesenchymal States Unlinks EMT from Metastasis-Enhancing Stem Cell Capacity. Cell Reports. 2016; 14:2281-88. https://doi.org/10.1016/j. celrep.2016.02.034.

55. Sulaiman A, McGarry S, Li L, Jia D, Ooi S, Addison C, Dimitroulakos J, Arnaout A, Nessim C, Yao Z, Ji G, Song H, Gadde S, et al. Dual inhibition of Wnt and Yes-associated protein signaling retards the growth of triple-negative breast cancer in both mesenchymal and epithelial states. Mol Oncol. 2018; 12:423-40. https://doi. org/10.1002/1878-0261.12167.

56. Biddle A, Gammon L, Liang X, Costea DE, Mackenzie IC. Phenotypic plasticity determines cancer stem cell therapeutic resistance in oral squamous cell carcinoma. EBioMedicine. 2016; 4:138-45. https://doi.org/10.1016/j. ebiom.2016.01.007.

57. Setúbal Destro Rodrigues MF, Gammon L, Rahman MM, Biddle A, Nunes FD, Mackenzie IC. Effects of Cetuximab and Erlotinib on the behaviour of cancer stem cells in head and neck squamous cell carcinoma. Oncotarget. 2018; 9:13488-500. https://doi.org/10.18632/oncotarget.24416.

58. Strauss R, Li ZY, Liu Y, Beyer I, Persson J, Sova P, Möller T, Pesonen S, Hemminki A, Hamerlik P, Drescher C, Urban N, Bartek J, Lieber A. Analysis of epithelial and mesenchymal markers in ovarian cancer reveals phenotypic heterogeneity and plasticity. PLoS One. 2011; 6:e16186. https://doi.org/10.1371/journal.pone.0016186. Erratum in: PLoS One. 2011; 6. https://doi.org/10.1371/ annotation/8c637352-3614-406c-89dc-e78d10fa069c.

59. Hojo N, Huisken AL, Wang H, Chirshev E, Kim NS, Nguyen SM, Campos H, Glackin CA, Ioffe YJ, Unternaehrer JJ. Snail knockdown reverses stemness and inhibits tumour growth in ovarian cancer. Sci Rep. 2018; 8:8704. https://doi.org/10.1038/s41598-018-27021-z.

60. Jolly MK, Kulkarni P, Weninger K, Orban J, Levine H. Phenotypic Plasticity, Bet-Hedging, and Androgen Independence in Prostate Cancer: Role of Non-Genetic Heterogeneity. Front Oncol. 2018; 8:50. https://doi. org/10.3389/fonc.2018.00050.

61. Brock A, Chang H, Huang S. Non-genetic heterogeneity-a mutation-independent driving force for the somatic evolution of tumours. Nat Rev Genet. 2009; 10:336-42. https://doi.org/10.1038/nrg2556.

62. Goldman A, Majumder B, Dhawan A, Ravi S, Goldman D, Kohandel M, Majumder PK, Sengupta S. Temporally sequenced anticancer drugs overcome adaptive resistance by targeting a vulnerable chemotherapy-induced phenotypic transition. Nat Commun. 2015; 6:6139. https://doi.org/10.1038/ ncomms7139.

63. Zhao D, Mo Y, Li MT, Zou SW, Cheng ZL, Sun YP, Xiong Y, Guan KL, Lei QY. NOTCH-induced aldehyde dehydrogenase $1 \mathrm{~A} 1$ deacetylation promotes breast cancer stem cells. J Clin Invest. 2014; 124:5453-65. https://doi. org/10.1172/JCI76611.

64. Jia D, Jolly MK, Boareto M, Parsana P, Mooney SM, Pienta KJ, Levine H, Ben-Jacob E. OVOL guides the epithelialhybrid-mesenchymal transition. Oncotarget. 2015; 6:15436-48. https://doi.org/10.18632/oncotarget.3623.

65. Hong T, Watanabe K, Ta CH, Villarreal-Ponce A, Nie Q, Dai X. An Ovol2-Zeb1 mutual inhibitory circuit governs bidirectional and multi-step transition between epithelial and mesenchymal states. PLoS Comput Biol. 2015; 11:e1004569. https://doi.org/10.1371/journal.pcbi.1004569.

66. Watanabe K, Villarreal-Ponce A, Sun P, Salmans ML, Fallahi M, Andersen B, Dai X. Mammary morphogenesis and regeneration require the inhibition of EMT at terminal end buds by Ovol2 transcriptional repressor. Dev Cell. 2014; 29:59-74. https://doi.org/10.1016/j.devcel.2014.03.006.

67. Jolly MK, Tripathi SC, Jia D, Mooney SM, Celiktas M, Hanash SM, Mani SA, Pienta KJ, Ben-Jacob E, Levine H. Stability of the hybrid epithelial/mesenchymal phenotype. Oncotarget. 2016; 7:27067-84. https://doi.org/10.18632/ oncotarget.8166.

68. Dang TT, Esparza MA, Maine EA, Westcott JM, Pearson GW. $\triangle \mathrm{Np} 63 \alpha$ promotes breast cancer cell motility through the selective activation of components of the epithelial-to-mesenchymal transition program. Cancer Res. 2015; 75:3925-35. https://doi.org/10.1158/0008-5472. CAN-14-3363. 
69. Bocci F, Jolly MK, Tripathi SC, Aguilar M, Hanash $\mathrm{SM}$, Levine H, Onuchic JN. Numb prevents a complete epithelial-mesenchymal transition by modulating Notch signalling. J R Soc Interface. 2017; 14:20170512. https:// doi.org/10.1098/rsif.2017.0512.

70. Mooney SM, Talebian V, Jolly MK, Jia D, Gromala M, Levine H, McConkey BJ. The GRHL2/ZEB Feedback Loop-A Key Axis in the Regulation of EMT in Breast Cancer. J Cell Biochem. 2017; 118:2559-70. https://doi. org/10.1002/jcb.25974.

71. Boareto M, Jolly MK, Goldman A, Pietilä M, Mani SA, Sengupta S, Ben-Jacob E, Levine H, Onuchic JN. NotchJagged signalling can give rise to clusters of cells exhibiting a hybrid epithelial/mesenchymal phenotype. J R Soc Interface. 2016; 13:20151106. https://doi.org/10.1098/rsif.2015.1106.

72. Lu M, Jolly MK, Levine H, Onuchic JN, Ben-Jacob E. MicroRNA-based regulation of epithelial-hybrid-mesenchymal fate determination. Proc Natl Acad Sci U S A. 2013; 110:18144-49. https://doi.org/10.1073/pnas.1318192110.

73. Clewley R. Hybrid models and biological model reduction with PyDSTool. PLoS Comput Biol. 2012; 8:e1002628. https://doi.org/10.1371/journal.pcbi.1002628.

74. Hunter JD. Matplotlib: A 2D graphics environment. Comput Sci Eng. IEEE. 2007; 9:90-5. 